\title{
DIGITALISATION OF HUMAN RESOURCE MANAGEMENT. KEY ROLES AND RELEVANT ISSUES FOR MILITARY ORGANISATIONS
}

\author{
Alina-Elena HULUBA (IONAȘCU) \\ "Carol I" National Defence University, Bucharest, Romania \\ ionascu.alina.03@gmail.com
}

\begin{abstract}
Many recent studies focus on the issue of interdependence relationship between the successful management of human resource and the improvement of organisational performance, under the aegis of key advances in technologies and information. Therefore, the digitalisation of human resource management is a hotly debated topic, with researchers focusing on the importance of this process within the organisations. The general intention of the author of this paper is to provide those interested with conceptual clarifications on electronic human resource management (e-HRM), by reference to the literature. From a specific point of view, the paper aims to highlight the relevant aspects of the digitalisation of human resource management in military organisations.
\end{abstract}

\section{Keywords: human resource management, digitalisation, e-HRM, military organisations}

\section{Introduction}

The new concerns about the impact of the use of technology on human resources analyses how digitalisation influences recruitment, selection, training and assessment processes. The general argument is that the integration of electronic monitoring software and systems, namely the use of social networks, applications, platforms and smart devices in human resource management processes, facilitates the increase of personnel quality and encourages performance.

In light of these considerations, most studies are interested in the issue of the extent to which the digitalisation has a positive impact on human resources. Therefore, it becomes useful for this paper to explore how to understand the use of digital tools at the level of process-specific practices associated with human resource management. For this, the paper has a homogeneous structure for a conceptualtheoretical and thematic point of view. The conceptual approach is found in the first section and aims to understand the perspectives in the literature on the significance of digitising human resource management. The second section identifies the digital tools and the key roles they play in the process associated with human recourse management. In the third section, the paper tries to address the issue of digitalisation of human resource management in military organisations, focusing on relevant issues from the perspective of the particularities of this field of activity.

Therefore, the increasing use of technologies influence the development of processes associated with human resource management, organisations aiming to develop a strong resilience to the continuous evolution in this field, so as to adapt to the new realities while maintaining a state of normality.

\section{Conceptual clarifications}

In a century of constantly changing digital technologies, the paradigm of computer systems used, usually for storing, 
processing and distributing employeerelated information, is no longer appropriate to understand how the integration of cloudbased systems, social media or gaming influences human resource management (HRM). In this context, more and more studies are focusing on the influence of online approaches in HRM policies and practices on the performance of employees and organisations. Raymond A. Noe (2016) and his collaborators state that the technologies capable of processing and transmitting digitised information associated with HRM from a computer of electronic device to those interested, influence specific aspects of human resources, such as: planning, attracting, recruiting, training, employee assessment and reward. At the same time, they mention that social media applications and opportunities offered by new technologies based on client-server architecture supported by related databases are among the most important elements of digital systems that facilitate human resource management through electronic HRM (eMRU) [1]. Several studies have focused on clarifying this concept from the perspective of the extent to which digital tools and influence the future of human resource management. Referring to the impact of digital transformations on HRM, Betchoo Nirmal Kurmal (2016) promotes the idea that new technologies have an important influence on human resource management [2], while a cross-sectional analysis by Tanvi Rana (2019), argues that e-HRM refers to an integrated, organisation-wide electronic network of information, services, devices, applications and human resource exchanges that implement organisational strategies [3]. During these studies, it is argued that e-HRM does not only refer to computer systems and software, but is related to the implications of using tools such as social media, web applications/platforms and cloud databases, which have a radical impact on human resources. In this sense, a systematic review of the literature was carried out by Strohmeier Stefan (2020) whose conceptual clarifications on the digitalisation of resource management are based on its result [4]. Thus, according to its meaning, the digitalisation of HRM is a technical process, involving the conversion of analogue information specific to human resources into digital information that can be processed automatically and a social process, because it allows the exploitation of the technological potential, the ultimate goal being the fulfilment of operational and strategic missions of this function, at organisational level.

Although this brief review includes in an acceptable manner the conceptual essence of the HRM digitalisation process, it becomes useful to analyse how the use of digital tools influences the processes associated with HRM, and what are their most relevant aspects from the perspective of military organisations, whose transformation has particular implications, generated by the specific nature of the missions they have to fulfil in safe conditions in the physical, informational or cyber environment.

\section{Digital tools and processes associated with HRM. Key roles}

The digitalisation of human resource management involves all processes: from recruitment and selection, to training and assessment, including those related to performance, motivation or reward. This requires the deduction of the idea that digital tools influence human resources, which makes it important to identify the most relevant and describe how they facilitate the development of the processes associated with HRM.

In a personal sense, in addition to the software packages that are indispensable for organisations that want the optimised storage and processing of employee information, social platforms (Facebook, Instagram, Twitter), mobile applications, (Whatsapp, Telegram), smart devices such 
as smart watches, games, whose purpose is to get acquainted with the history, organisation chart and strategy of organisations, cloud facilities and electronic support systems at work, can be categorised as digital tools specific to HRM Such an integrated technological image allows the development of processes associated with HRM in conditions of efficiency, by managing information in the virtual environment.

In the recruitment and selection process, the key role played by the digital tools is to identify and choose the most suitable employees. The social networks, such as Facebook and Twitter, are used by recruiters of organisations to promote their offer and select employees whose profile meets the requirements.

During the human resource training process, it has become increasingly clear that digital tools have a key role to play in facilitating the infusion of knowledge among employees, beyond the constraints of space and event time.

From this point of view, Pantelidis Ioannis (2019) states that the electronic training involves 'the use of mixed learning methods, supported by digital platforms, in order to support the development of knowledge and skills in an organisation'. Moreover, he argues that by associating the electronic learning with metadata systems, the decision makers can see in real time what training programs are working and what issues need to be adjusted, respectively to receive automatic information on employee weaknesses and how they can be minimised while maximising strengths [5].

In this case, web platforms allow for the conduct of courses and workshops for human resources and metadata are responsible for the important role of supporting the potential of employees to grow. At the same time, a very important role is played by the games that allow both the assimilation of knowledge about the organisation and the simulation of specific activities.

Regarding the assessment of human resources, the key role of the digitised tools is represented by electronic performance monitoring (e-performance). In the same paper, Pantelidis states that e-performance is 'a continuous process of digitally supported communication between managers and employees, which helps achieve the strategies objectives of the organisation, while ensuring the employee engagement and motivation are maximised'. He argues that online profiles facilitate the analysis of performance against the benchmarks of best practices, the results obtained being reward catalysts, which lead to an increased involvement of human resources [6]. In this case, the most important systems are the performance monitoring systems, which can be specially designed at the level of organisations to increase the monitoring capabilities of employees and support them with necessary feedback so that they meet their objectives. The personalised feedback or promotion of the best employees through social platforms or organisational forums, contributes to their motivation and increases their involvement at the workplace. However, smart personnel monitoring devices also play an important role, which prove to be effective if used in compliance with organisational ethics. Specifically, the employee is informed on how his/her activity is monitored. According to Pantelidis, they are known as the Internet of Things (IoT). Given these issues, I believe that the advantage of the smart devices for collecting data on the personnel activity is given by the accuracy of the data, based on which managers can make the right decisions on improving a business, redesigning the requirements of the position, supplementing positions in that structure or rewarding the employee. This position is also supported by Connellya Chaterine (2020), according to which the use of technological systems in 
performance monitoring processes allows a clear differentiation between employees, compared to the traditional method based on the findings of the supervisor [7].

Therefore, the digital tools mentioned at the beginning of this section have defined roles in the processes associated with HRM, being a catalyst for the simplification of personnel activities. The transparency in their use allows employees and managers to maintain a successful climate, through the attention paid to the personalised adjustment of training programs and closer monitoring of the work carried out by it. Thus, the digitalisation of human resource management is in itself a desideratum for modern companies and institutions, including military organisations.

\section{Relevant aspect through the digitalisation of HRM in military organisations}

Given that the literature in the field of military science highlights the existence of confrontational environments of impact, such as computer space, virtual space and psychological space, it is understandable that human resource management in military organisations must rally with new technologies to general optimal answers to complex problems. For example, during the Cold War, the competition in the field of technology and the inability of the Soviet side to compete with the Western alliance in the field of computers, have determined the outcomes of this confrontation in the favour of the West. Consequently, the technological evolution involves new capabilities that have an impact not only on the nature of future confrontations, but also on the role of human resources.

Being a beneficial social and technical process for private companies and state institutions, because it is associated with increasing efficiency, reducing administrative burdens and performance, the digitalisation of human resource management is also on the agenda of military organisations. Considering the key roles identified in the section above, it is necessary to identify the major attributes of the digitalisation process of HRM in military organisations. Thus, the paper focuses on three relevant aspects of e-HRM in military organisations.

Firstly, it can be said that one of its main distinguishing features is to be designed transparently through digital tools specific to the new generation of potential recruits. The human resource practices that are considered in terms of e-HRM at the level of military organisations depend on the use of digital tools so that they are compatible with the legislative and deontological requirements specific to the military environment. For example, the use of social networks and websites to promote the recruitment and training of military personnel involves the publication of data in the form of text, photos or videos, which become available online and accessible. It is obvious that using digital tools familiar to the new generation, military organisations are consolidating their image as an attractive employer among contemporary youth. This can create a positive image, which also attracts the right people for the military organisation adapted to the increasing complexity of the labour market. However, when we talk about such an exposure, one thing to note is that these data accessible to all can develop in the opinion of the general public, and depending on the degree of alignment with the specific limitations of the military environment, can facilitate challenges and contribute to strengthening the status of the armed forces in the eyes of the state citizens.

Secondly, the integration of e-HRM in military organisations depends unequivocally on the analysis of security risks in the virtual environment. If in organisations outside this field of activity, human resource management processes can be performed using digital tools and computerised or mobile systems anywhere and anytime, in the case of military 
organisations, their realisation is possible only at the premises. Practically, in military organisations the digitalisation of human resource management considers mainly the integration of specially designed software systems, the other tools being used so as not to form a weak link in relation to the susceptible cybernetic and security risks. Thus, direct changes in human resource management in military organisations involve working procedures and algorithms in accordance with data and information security policies and practices. Therefore, for military organisations, the identification of employees at risk of exposure in the online environment has become a priority.

Thirdly, the digitalisation of human resource management in military organisations must take into account that new technologies specific to robotics, artificial intelligent and smart devices will have a major influence on the successful professional training of military personnel. This is supported by the predictions of O'Hanlon (2018) according to which these are key tools that will have a revolutionary impact over the next 20 years, the argument being based on the integration of technological advances in the biological field [8]. Of course, depending on how they are used, they can generate positive or negative effects. In this sense, Biling together with other researchers (2020) bring to the attention the impact that monitoring the real physiological state (RT-PSM) of soldiers can have, in relation to individual and team performance, respectively to the outcome of military actions. They argue that such a tool can be useful in training individual and group performance, but in operational environments, such technology is simply a distraction, unless it provides vital information that can help military decision-makers makes to make decisions adapted to field conditions, in real time [9]. Therefore, the relevant issues regarding the digitalisation of HRM in military organisations take into account the evolution of digital tools that can contribute to increasing the effectiveness of human resource management, but also a number of weaknesses that can affect both individual and organisational integrity. These issues become all more relevant in military organisations, because confidentiality and discipline are so vulnerable in the virtual environment, they are essential pillars for successful specific activities.

\section{Conclusions}

In contemporary society, technology makes it possible to perform activities that were once hard to imagine. Moreover, the integration of digitised tools into human resources practices should support the 'smart' implementation of human resource management processes.

The digital tools have key roles in human resource management, the quintessence of which is to reshape the processes of recruitment, selection, training, motivation, assessment and reward of personnel in accordance with the organisational strategy applied with the help of technological advances. Thus, the concept of e-HRM was developed, as a social and technical process well advanced, which has the potential to facilitate the achievement of strategic objectives in terms of performance.

Regarding the digitalisation of human resource management, the problem could be shaped around the balance of technological facilities and architectural limitations of a legal and cultural nature specific to the field of defence. In this sense, I believe that digitalisation involves the analysis of the most relevant aspects related to transparency, legality, culture, etc. and drawing up operational procedures to increase efficiency in the event of cybernetic, informational or disciplinary anomalies.

Finally, the digitalisation involves a distinct approach for each organisation, which is based on focusing on the key roles of digital tools in relation to human resources, expected organisational results and institutional particularities. 


\section{References List}

[1] Noe R.A., John R. H., Barry G., Patrick M. W., Linda E. Strategic Human resource management: gaining a competitive advantage. New York: McGraw Hill Education, 2016.

[2] Strohmeier S. Digital human resource management: A conceptual clarification. German Journal of Human Resource Management. 2020, vol. 34. pp. 345-365.

[3] Betchoo, N. K. Digital Transformation and its impact on Human Resource Management. A Case Analysis of two unrelated businesses in the Mauritian public service. International Conference on Emerging Technologies and Innovative Business Practices for the Transformation of. Mauritius, Publishing House of the Institute of Electrical and Electronic Engineers, 2016.

[4] Tanvi, R. Digitization of Human Resource Practices - An Emerging. Proceedings of 10th International Conference on Digital Strategies for Organizational Success. Navi Mumbai, 2019, pp. 1173-1183.

[5] Pantelidis, I. S. Digital Human Resource Management. Londra: Routledge, 13.08.2019, accessed on 06.03. 2021. Available from: https://cris.brighton.ac.uk/ws/portalfiles/porta 1/6831955/Digital Human Resource Management.pdf.

[6] Pantelidis, I. S. Digital Human Resource Management. Londra: Routledge, 13.08.2019, accessed on 06.03. 2021. Available from: https://cris.brighton.ac.uk/ws /portalfiles /portal/6831955/Digital_Human_Resource_Management.pdf.

[7] Connellya C. E., Fieselerb C., Matej Č., Steffen R. G., Sut I W. Working in the digitized economy: HRM theory \& practice. Human Resource Management Review, 2020, vol. 31.

[8] O'Hanlo, M. A Retrospective on the so-called revolution in military affairs, 2000-2020. Washington: Brookings, 2018.

[9] Billing, D.C., Graham R. F., Karl E. F., Hasselstromd H. The implications of emerging technology on military human performance research priorities. Journal of Science and Medicine in Sport, 2020. 